\title{
Control Yourself: Physical Education Teachers' Emotional Intelligence Has a Minor Role in Pupils' Need Satisfaction
}

\author{
Matthew Watson*, Jens Kleinert \\ Institute of Psychology, German Sport University Cologne, Cologne, Germany \\ Email: ^m.watson@dshs-koeln.de
}

How to cite this paper: Watson, M., \& Kleinert, J. (2017). Control Yourself: Physical Education Teachers' Emotional Intelligence Has a Minor Role in Pupils' Need Satisfaction. Advances in Physical Education, 7,234-247.

https://doi.org/10.4236/ape.2017.73019

Received: May 12, 2017

Accepted: July 11, 2017

Published: July 14, 2017

Copyright $\odot 2017$ by authors and Scientific Research Publishing Inc. This work is licensed under the Creative Commons Attribution International License (CC BY 4.0).

http://creativecommons.org/licenses/by/4.0/

\begin{abstract}
Purpose: There is a lack of empirical evidence concerning emotional intelligence (EI) in physical education (PE) teachers. From a basic needs theory perspective (Ryan \& Deci, 2000), this study aimed to examine the role of PE teachers' EI in perceiving and supporting pupils' need satisfaction. Method: Within this cross-sectional study, 319 pupils from $14 \mathrm{PE}$ classes were each administered a Contextual Basic Need Satisfaction questionnaire for PE (CBANS) and Sport Climate Questionnaire. Correspondingly, PE teachers were administered a Trait Emotional Intelligence Questionnaire-Short Form and CBANS from their pupils' perspective. Results. Analyses revealed that PE teachers' EI self-control significantly positively predicted the accuracy of their perceptions of pupils' relatedness satisfaction. No other significant relationships emerged. Discussion/Conclusion: These findings repudiate a direct role of PE teachers' EI in supporting pupils' motivation. However, the control of one's own emotion appears to be important for teachers to perceive need satisfaction in pupils.
\end{abstract}

\section{Keywords}

Emotional Intelligence, Physical Education, Basic Psychological Need Satisfaction, Autonomy Support

\section{Introduction}

Physical education (PE) classes are emotionally charged environments that require teachers to utilise an array of intrapersonal and interpersonal emotional skills (Mouratidis, Vansteenkiste, Lens, \& Vanden Auweele, 2009; Sutton \& Wheatley, 2003). However, there is a lack of research examining the relevant construct of emotional intelligence (EI) in PE teachers. Teachers' emotional competencies 
are integral to their ability to establish respectful, responsive and engaged classroom conditions (Jennings \& Greenberg, 2009) and to preserve their own emotional state (Jennings \& Greenberg, 2009; Tsouloupas, Carson, Matthews, Grawitch, \& Barber, 2010). Moreover, pupils' motivation towards PE, a critical consideration as it impacts sport participation both in and outside of school (Ntoumanis, 2005; Goudas, Dermitzaki, \& Bagiatis, 2001), appears to be impacted more by their perceptions of PE teachers' emotional behaviours than by their peer relationships (Cox, Duncheon, \& McDavid, 2009). The construct of EI comprises a multitude of essential skills for PE teachers, but as of yet it has not been empirically examined in conjunction with outcomes of relevance to pupils' motivation. The purpose of the current study, therefore, is to examine the role of $\mathrm{PE}$ teachers' $\mathrm{EI}$ in the perception and support of pupils' motivation.

In order to clearly examine the role of PE teachers' EI, it is necessary to define EI and its dimensions. Whilst EI is commonly described as one's identification, expression, understanding, regulation, and use of intrapersonal and interpersonal information (Brasseur, Grégoire, Bourdu, \& Mikolajczak, 2013; Mayer \& Salovey, 1997; Petrides \& Furnham, 2003), two distinct perspectives are found in the large majority of EI research: the ability perspective comprises trainable, cognitive abilities assessed via performance tests, whilst the trait perspective comprises relatively stable dispositions that exist at the lower level of personality hierarchies and is assessed via self-report questionnaires (Petrides, Pita, \& Kokkinaki, 2007). The current study employs the trait perspective of Petrides (2009b), as pupils' need satisfaction in PE is seen as contingent upon the personality traits demonstrated by teachers in lessons, rather than teachers' maximum performance regarding emotion. Specifically, Petrides outlines a global trait EI with four EI factors: emotionality (comprising items relating to emotion perception, empathy, and emotion expression), self-control (comprising emotion regulation, stress management, and low impulsiveness), sociability (comprising assertiveness, emotion management, and social awareness), and well-being (comprising happiness and optimism).

Numerous reports comment on the importance of teachers' emotional competencies (e.g. Jennings \& Greenberg, 2009), with quantitative findings showing positive associations with job satisfaction, personal accomplishment, and positive affect (Brackett, Palomera, Mojsa, Reyes, \& Salovey, 2010). Very few studies exist that examine trait EI in teachers, whilst only one study could be identified that examined trait EI in PE teachers specifically. Mouton, Hansenne, Delcour, and Cloes (2013) reported that PE teachers' trait EI, specifically sociability, predicted their teaching efficacy (i.e. their belief in their teaching abilities), a construct that has shown associations with pupil motivation, achievement, and efficacy (Tschannen-Moran, Woolfolk-Hoy, \& Hoy, 1998). Rarely, however, have teachers' emotional competencies been directly and empirically examined with regard to pupil outcomes. An exception to this is the study of Chang (2003), in which teachers' empathy was positively related to pupils' feelings of social competence, although this was limited to pupils' that were reported by their peers as 
socially withdrawn and is therefore less generalisable. In summary, the importance of teachers' emotional competencies, specifically in terms of trait EI and outcomes for pupils, has received insufficient empirical research attention to date.

A pertinent factor to examine in connection with $\mathrm{PE}$ teachers' $\mathrm{EI}$ is pupil motivation, particularly as described by basic needs theory (BNT; Ryan \& Deci, 2000). Itself a micro-theory of the widely used self-determination theory of motivation, BNT posits that humans possess three innate psychological needs that, depending on their level of satisfaction, essentially regulate the emotional state of an individual (Deci \& Ryan, 1985, 1987). These three needs, which have to be satisfied for well-being, growth, and positive development within particular situational contexts, are: the need for autonomy (i.e. feeling a sense of control regarding choices and decision-making and perceiving one's actions to complement one's integrated sense of self); the need for competence (i.e. feelings of mastery through effective interaction within one's environment); and the need for relatedness (i.e. feelings of belongingness to and respect by significant others; Ryan \& Deci, 2000). Pupils' need satisfaction in PE is an important aspect for teachers to consider as greater need satisfaction has favourable effects on pupils' concentration, preference for challenging tasks, and positive and negative affect (Standage, Duda, \& Ntoumanis, 2005).

A prominent determinant of pupils' need satisfaction in PE is the need-supportive behaviour, termed autonomy support, pupils perceive from their teacher (Taylor \& Ntoumanis, 2007). Mageau and Vallerand (2003)'s seminal definition of autonomy support, based on various works by Deci and Ryan (see Deci \& Ryan, 2000), describes a number of autonomy-supportive behaviours that require EI to identify and understand followers' emotional states, such as acknowledging subordinates' feelings, providing choice, and avoiding overtly controlling or guilt-inducing statements. Within the PE context, pupils' perceived autonomy support from their teacher positively predicts need satisfaction (Taylor \& Lonsdale, 2010). Additionally, pupils' perceived autonomy support in PE is an important outcome for teachers to consider as it links to pupils' physical activity behaviours outside of PE (i.e. in leisure time; Barkoukis \& Hagger, 2009).

Existing literature offers support for a role of PE teachers' trait EI in perceiving and satisfying pupils' basic needs. Pupils' need satisfaction in PE predicts self-reported positive and negative affect, typically measured using lists of emotional adjectives (e.g. disappointed, embarrassed; Ntoumanis, 2005), whilst pupils who report more self-determined motivation (characterised by greater need satisfaction) in PE also exhibit higher concentration and greater effort during class (Ntoumanis, 2005; Standage, Duda, \& Ntoumanis, 2005). These observable displays of emotion would be expected to be more perceivable to a PE teacher with higher levels of trait EI.

The identification of pupils' emotional states, as an important dimension of PE teachers' trait EI, appears to be helpful in supporting need satisfaction: Cox, Duncheon, and McDavid (2009) examined pupils' perceptions of how their 
teachers cared about and understood them, although using questionnaire items such as "does your PE teacher try to help you when you are sad or upset?" and "does your PE teacher really understand how you feel about things?" that appear synonymous with the emotion perception and empathy aspects of trait EI. Cox et al. reported that pupils' perceived support from their PE teachers linked to increased self-determined motivation. Furthermore, as previously alluded to, PE teachers' trait EI appears to be a relevant interpersonal antecedent of the provision of autonomy support. The autonomy-supportive behaviours outlined by Mageau and Vallerand (2003) require empathy, social awareness, and low impulsiveness. Other dimensions of trait EI, such as self-control, may also be relevant as research shows that PE teachers reduce their use of autonomy support when experiencing pressure (Taylor \& Ntoumanis, 2007).

In conclusion, there is a lack of empirical research examining the role of trait EI in PE teachers, despite the value of trait EI in other sport-related contexts (e.g. coaches; Chan \& Mallett, 2011; Laborde, Dosseville, \& Allen, 2016). The favourable outcomes of pupils' need satisfaction in PE, such as concentration and positive affect, along with the aforementioned connections between teachers' trait EI and the perception and support of pupils' needs, warrants the examination of teachers' trait EI with regard to pupils' need satisfaction. The current study will, therefore, examine the links between PE teachers' EI and teachers' perception of need satisfaction in pupils, pupils' reported need satisfaction and, finally, pupils' perceived autonomy support from their PE teacher. We hypothesise that: 1) PE teachers' EI will link to the accurate perception of pupils' need satisfaction; 2) that PE teachers' EI will show positive associations with need satisfaction in pupils; and finally, 3) that PE teachers' EI will show positive associations with pupils' perceived autonomy support, as the dimensions of emotional regulation and using underpin a number of autonomy-supportive behaviours.

\section{Method}

\subsection{Participants}

The sample, comprising teachers ( 7 female, 7 male; mean age $=36 \pm 9$ yrs; range $=28$ to $60 \mathrm{yrs}$ ) and pupils (154 female, 165 male; mean age $=13 \pm 1$ yrs; range = 11 to $16 \mathrm{yrs}$ ), was recruited from secondary schools in Germany. Each class consisted of a mean of $22.79(\mathrm{SD}=3.40)$ pupils. Classes had a mean of $2.42(\mathrm{SD}=$ $0.91)$ hours of PE per week. Teachers had a mean of $7.35(\mathrm{SD}=7.23)$ years of $\mathrm{PE}$ teaching experience, whilst pupils had been taught by their PE teachers for a mean of $1.20(\mathrm{SD}=1.14)$ years.

\subsection{Procedure}

Ethical approval for this study was provided by the local University. Briefly, PE teachers from secondary schools local to the University were sent an email inviting them to participate and introducing them to the study themes and requirements. Informed consent forms were then distributed by interested teachers to the parents or legal guardians of pupils, which were collected prior to 
completing questionnaires. A researcher met with participating teachers and school classes on one occasion, typically in a classroom setting as this was recommended by teachers as the most practical setting to complete questionnaires, wherein the teacher and pupils were instructed to answer each item truthfully and to avoid conferring. All participants were reminded that their responses would be treated confidentially and anonymously, whilst they may dropout without explanation at any point. Questionnaires were coded to distinguish between classes, then teachers and pupils within each class, but individual names were not linked with questionnaire packets. Researchers oversaw the completion of the questionnaires and were available to clarify questions if necessary.

\subsection{Measurements}

Pupils' basic need satisfaction. The German language Contextual Basic Need Satisfaction questionnaire for physical education (CBANS; Raven \& Kleinert, 2016) was used to assess pupils' basic need satisfaction in terms of a typical PE lesson with their teacher. The CBANS questionnaire currently comprises 11 items and 3 subscales: competence ( 3 items, e.g. "the teacher enabled me to experience progress and success"); relatedness ( 3 items, e.g. "the teacher gave me opportunities to feel belonging to something or somebody"); and autonomy (5 items, e.g. "the teacher gave me opportunities for free choice"), requiring responses on a four-point scale from 0 (not at all) to 3 (very true). The questionnaire's internal consistency has been shown to be acceptable in sport settings (Kleinert, 2012; Raven \& Kleinert, 2016). The reliability (Cronbach's Alpha) of each subscale in the present study was 0.74 (competence), 0.70 (relatedness) and 0.79 (autonomy).

Teachers' need empathy. The accuracy of teachers' perception of pupils' need satisfaction (hereafter termed "need empathy" for brevity), was operationalised by comparing each class's pupil-completed CBANS data with the CBANS questionnaire completed by its respective PE teacher (the calculation used to determine specific need empathy outcome variables is detailed in the data analysis section). Except for a modified instruction statement asking teachers to answer from their pupils' perspective ("Thinking about a typical physical education lesson you've led, how do you think your pupils would answer these statements?"), teacher-completed CBANS questionnaires and pupil-completed CBANS questionnaires were identical. Previous study protocols have similarly modified questionnaires to capture the perspectives of sports-leaders (e.g. Smith et al., 2016; Stebbings, Taylor, \& Spray, 2011).

Trait emotional intelligence. A German version of the Trait Emotional Intelligence Questionnaire-Short Form (TEIQue-SF) was used to measure teachers' EI (Freudenthaler, Neubauer, Gabler, Scherl, \& Rindermann, 2008). The TEIQue-SF is based on the long form of the TEIQue (Petrides, 2009a) and measures global trait EI and four subscales: emotionality (8 items, e.g. "Expressing my emotions with words is not a problem for me"), self-control (6 items, e.g. "I'm usually able to find ways to control my emotions when I want to"), well- 
being (6 items, e.g. "On the whole, I'm pleased with my life") and sociability (6 items, e.g. "I can deal effectively with people"). Participants respond to items on a 7-point Likert-scale from 1 (completely disagree) to 7 (completely agree). Following the reverse scoring of negative items, global/subscale values are determined by averaging the respective items, with higher scores reflecting higher trait EI. The internal reliability of the German TEIQue for global trait EI (0.96), emotionality (0.90), self-control (0.86), well-being (0.94) and sociability (0.88) has been reported elsewhere (Freudenthaler et al., 2008). Reliability values for the current study were not calculated due to the low number of teachers.

Autonomy support. The short form Sport Climate Questionnaire (SCQ), adapted from the Health Care Climate Questionnaire originally developed by Williams, Grow, Freedman, Ryan, and Deci (1996), was translated into German and used to measure the degree to which pupils perceived their teacher to be autonomy-supportive. The SCQ comprises six items (e.g. "I feel understood by my physical education teacher") that are answered on a 7-point Likert-scale from 1 (strongly disagree) to 7 (strongly agree). The average of the six responses provides the perceived autonomy support score. The reliability of the questionnaire for this sample was found to be good $(\alpha=0.88)$.

\subsection{Data Analysis}

IBM SPSS Statistics 23 was used to assess the distribution of data and subsequent correlations. Missing pupil data were not included in either the correlation or multilevel analyses.

Shapiro-Wilk tests of normality for pupil-level variables (i.e. $n=319$ ) indicated that data were not normally distributed and, therefore, correlations involving these were computed with Spearman's Rank correlations, multiplying out teacher-level (i.e. $\mathrm{n}=14$ ) variables accordingly.

The hypotheses of this study were tested according to their multilevel structure using Hierarchical Linear Modeling (HLM). As indicated by Raudenbush and Bryk (2002), pupils in classes should be considered as similar to each other, or "nested" within their respective classes, as each class is influenced by their respective teacher. Proceeding to analyse hierarchically structured data under the assumption that observations are independent of each other, using ANOVA or $t$-tests for example, greatly increases the risk of making a type I error. Moreover, as multilevel models prevent the aggregation of data to the class level they preserve the power and variance of the sample. Finally, sample sizes of 10 or more level 2 units are recommended when running multilevel analyses (Nezlek, 2008).

To test hypothesis 1, the differences between pupils' CBANS responses and their respective teacher's CBANS responses were determined and used to represent the teachers' "need empathy". More precisely, for each CBANS subscale (i.e. competence, relatedness, autonomy), the absolute difference (i.e. the distance) between pupils' responses and teachers' responses were computed and then reversed to give a range from 0 (i.e. minimum accuracy of need empathy) to 3 (i.e. maximum accuracy of need empathy). Thus, three level-1 outcome variables were created: "competence-empathy", "relatedness-empathy" and "autono- 
my-empathy".

To test hypothesis 2, the three subscales of the pupils' CBANS responses (i.e. their need satisfaction without integration with the teachers' CBANS responses) were tested separately as level-1 outcome variables.

To test hypothesis 3, perceived autonomy support (SCQ) was tested as the level-1 outcome variable.

Predictor variables for all hypotheses were level-2, or "teacher level", variables, specifically global EI and EI subscales (i.e. emotionality, self-control, well-being and sociability). EI variables were individually entered into separate models to avoid entering the same data twice. It should be noted that, for HLM analyses, level-2 variables are multiplied out to match the level-1 $\mathrm{n}$ within each class.

\section{Results}

Table 1 shows the step-by-step approach to creating the need empathy outcome variables and provides an impression of how teachers estimate pupil need satisfaction as a class. Positive values in the difference column represent overestimation of teachers with regard to pupil needs, although these values were relatively small.

Correlations between variables and descriptive statistics are shown in Table 2. Pupils' perceived autonomy support from the teacher (SCQ) showed significant correlations with pupils' mean CBANS values for competence (0.656; $p<0.01)$, relatedness $(0.505 ; p<0.01)$ and autonomy $(0.564 ; p<0.01)$.

Using HLM, the between-class variation in each of the seven outcome variables (i.e. need empathy variables, pupil need satisfaction variables, pupils' perceived autonomy support), was first established by testing unconditional models (i.e. models without predictor variables). The resulting intraclass correlation (ICC) values for competence-empathy ( $\rho=0.11, p<0.001)$, relatedness-empathy ( $\rho=0.25, p<0.001)$, autonomy-empathy $(\rho=0.07, p<0.001)$, pupil competence ( $\rho=0.09, p<0.001)$, pupil relatedness $(\rho=0.013, p<0.001)$, pupil autonomy $(\rho$ $=0.10, p<0.001)$ and perceived autonomy support $(\rho=0.42, p<0.001)$ were calculated.

To test hypothesis 1 (i.e. that teachers with higher EI would more accurately perceive the need satisfaction of their pupils), level-2 predictor variables were added grand-mean centered into the unconditional model of each need empathy

Table 1. Mean responses for need satisfaction (CBANS).

\begin{tabular}{ccccccccccc}
\hline & \multicolumn{2}{c}{$\begin{array}{c}\text { 1. Pupil } \\
\text { CBANS }\end{array}$} & \multicolumn{2}{c}{$\begin{array}{c}\text { 2. Teacher } \\
\text { CBANS }\end{array}$} & \multicolumn{2}{c}{ 3. Difference } & \multicolumn{2}{c}{ 4. Distance } & \multicolumn{2}{r}{ 5. Need empathy } \\
\hline & Mean & SD & Mean & SD & Mean & SD & Mean & SD & M & SD \\
\hline Competence & 2.02 & 0.61 & 2.19 & 0.46 & 0.17 & 0.72 & 0.54 & 0.51 & 2.46 & 0.51 \\
Relatedness & 2.13 & 0.65 & 2.33 & 0.38 & 0.20 & 0.76 & 0.62 & 0.49 & 2.38 & 0.49 \\
Autonomy & 1.73 & 0.64 & 1.77 & 0.61 & 0.04 & 0.94 & 0.73 & 0.60 & 2.27 & 0.60 \\
\hline
\end{tabular}

Note: ${ }^{\mathrm{a}}$ Mean of team means; $\mathrm{SD}=$ standard deviation; 3. = Teacher CBANS-Pupil CBANS; 4. = Absolute values of 3; 5. = Reversed values of 4 . 
Table 2. Correlations between variables and descriptive statistics.

\begin{tabular}{|c|c|c|c|c|c|c|c|c|c|c|c|c|c|c|c|c|}
\hline & $\mathrm{n}$ & Mean & SD & Range & 1 & 2 & 3 & 4 & 5 & 6 & 7 & 8 & 9 & 10 & 11 & 12 \\
\hline 1. Pupil Competence & 315 & 2.02 & 0.61 & $0.00-3.00$ & - & & & & & & & & & & & \\
\hline 2. Pupil Relatedness & 314 & 2.13 & 0.65 & $0.33-3.00$ & $0.497^{* *}$ & - & & & & & & & & & & \\
\hline 3. Pupil Autonomy & 315 & 1.73 & 0.64 & $0.00-3.00$ & $0.524^{* *}$ & $0.458^{* *}$ & - & & & & & & & & & \\
\hline 4. Autonomy Support & 316 & 5.03 & 1.24 & $1.33-7.00$ & $0.656^{* *}$ & $0.505^{* *}$ & $0.564^{* *}$ & - & & & & & & & & \\
\hline $\begin{array}{c}\text { 5. Competence- } \\
\text { Empathy }\end{array}$ & 315 & 2.46 & 0.51 & $0.00-3.00$ & $0.261^{* *}$ & 0.092 & $0.201^{* *}$ & $0.186^{* *}$ & - & & & & & & & \\
\hline $\begin{array}{l}\text { 6. Relatedness- } \\
\text { Empathy }\end{array}$ & 314 & 2.38 & 0.49 & $0.67-3.00$ & $0.155^{* *}$ & $0.389^{* *}$ & $0.149^{* *}$ & $0.117^{*}$ & $0.243^{* *}$ & - & & & & & & \\
\hline $\begin{array}{l}\text { 7. Autonomy- } \\
\text { Empathy }\end{array}$ & 315 & 2.27 & 0.60 & $0.00-3.00$ & 0.095 & 0.062 & $0.142^{*}$ & 0.060 & $0.316^{* *}$ & $0.208^{* *}$ & - & & & & & \\
\hline 8. Teacher Global EI & 14 & 5.6 & 0.30 & $5.20-6.03$ & 0.005 & 0.045 & 0.001 & 0.074 & -0.068 & $0.123^{*}$ & $0.196^{*}$ & - & & & & \\
\hline $\begin{array}{l}\text { 9. Teacher EI } \\
\text { Emotionality }\end{array}$ & 14 & 5.88 & 0.50 & $5.13-6.88$ & 0.026 & $0.139^{*}$ & 0.061 & $0.146^{* *}$ & -0.042 & -0.037 & 0.048 & $0.588^{* *}$ & - & & & \\
\hline $\begin{array}{l}\text { 10. Teacher EI } \\
\text { Self-Control }\end{array}$ & 14 & 5.49 & 0.64 & $4.43-6.33$ & 0.028 & -0.011 & 0.051 & $0.121^{*}$ & 0.097 & $0.164^{* *}$ & $0.273^{* *}$ & $0.669^{* *}$ & 0.103 & - & & \\
\hline $\begin{array}{l}\text { 11. Teacher EI } \\
\text { Well-Being }\end{array}$ & 14 & 6.37 & 0.44 & $5.33-6.83$ & -0.045 & 0.043 & -0.009 & 0.025 & $-0.135^{*}$ & 0.054 & 0.062 & $0.690^{* *}$ & $0.511^{* *}$ & $0.240^{* *}$ & - & \\
\hline $\begin{array}{l}\text { 12. Teacher EI } \\
\text { Sociability }\end{array}$ & 14 & 5.48 & 0.53 & $4.17-6.17$ & -0.064 & -0.105 & $-0.168^{* *}$ & ${ }^{*}-0.131^{*}$ & -0.007 & $0.121^{*}$ & 0.086 & $0.373^{* *}$ & $-0.343^{* *}$ & $0.439^{* *}$ & 0.006 & - \\
\hline
\end{tabular}

Note: $\mathrm{SD}=$ standard deviation; higher values for empathy variables indicate closer responses between teacher and pupil CBANS. ${ }^{*} p<0.05,{ }^{* *} p<0.01$.

outcome variable. Within these regression with means as outcomes models, a significant relationship emerged between EI self-control and relatedness-empathy $\left(\mathrm{b}=0.14, p<0.05, \mathrm{r}^{2}=0.41\right)$.

To test hypothesis 2 (i.e. that pupil need satisfaction would be higher in classes with higher EI teachers), level-2 predictor variables were added grand-mean centered into the unconditional model of each pupil need satisfaction outcome variable. No main effects were found between pupil need satisfaction subscales and level-2 predictor variables.

Finally, to test hypothesis 3 (i.e. that pupils' perceived autonomy support would be higher in classes with higher EI teachers), level-2 predictor variables were added grand-mean centered into the unconditional model of the pupils' perceived autonomy support outcome variable. Again, no main effects were found between pupil autonomy support and level-2 predictor variables. Model statistics for all model variations are presented in Table 3.

\section{Discussion}

This paper aimed to examine the relationship between PE teachers' trait EI and the perception and support of pupils' need satisfaction within the PE context. Overall, our results do not offer comprehensive support for a role of PE teachers' trait EI in the satisfaction of pupils' basic needs. Specifically, HLM analyses revealed a significant positive relationship between PE teachers' trait EI self-control and their relatedness-empathy, thus only partially supporting our first hypothesis. Neither our second or third hypotheses were supported, however, as no significant relationships were found between EI variables and pupils' need satis- 
Table 3. Model statistics for unconditional and means-as-outcomes models.

\begin{tabular}{|c|c|c|c|c|c|c|c|c|}
\hline \multirow[b]{2}{*}{ Variables } & \multicolumn{4}{|c|}{ Unconditional Model } & \multicolumn{4}{|c|}{ Regression with Means-as-Outcomes Model } \\
\hline & Coefficient & $S E$ & $T$ & Deviance & Coefficient & $S E$ & $T$ & Deviance \\
\hline 1) DV: Pupil Competence & 2.025475 & 0.059214 & $34.206^{* * *}$ & 568.937694 & & & & \\
\hline L2 IV: EI & & & & & 0.016416 & 0.218795 & 0.075 & 568.333049 \\
\hline 2) DV: Pupil Relatedness & 2.140620 & 0.071398 & $29.982^{\star * *}$ & 603.882252 & & & & \\
\hline L2 IV: EI & & & & & 0.058319 & 0.263621 & 0.221 & 606.536163 \\
\hline 3) DV: Pupil Autonomy & 1.724445 & 0.064398 & $26.778^{\star * *}$ & 606.226350 & & & & \\
\hline L2 IV: EI & & & & & -0.077580 & 0.237386 & -0.327 & 605.352428 \\
\hline 4) DV: Competence Empathy & 2.458586 & 0.073822 & $33.304^{\star * *}$ & 418.995485 & & & & \\
\hline L2 IV: EI & & & & & -0.168562 & 0.267312 & -0.631 & 417.575141 \\
\hline 5) DV: Relatedness Empathy & 2.377447 & 0.043377 & $54.809^{* * *}$ & 431.589738 & & & & \\
\hline L2 IV: EI & & & & & 0.085704 & 0.158427 & 0.541 & 434.995265 \\
\hline L2 IV: EI Self-Control & & & & & 0.136388 & 0.060643 & $2.249^{*}$ & 432.742204 \\
\hline 6) DV: Autonomy Empathy & 2.273385 & 0.108527 & $20.948^{* * *}$ & 446.849134 & & & & \\
\hline L2 IV: EI & & & & & 0.573087 & 0.363254 & 1.578 & 442.785987 \\
\hline 7) DV: Perceived Autonomy Support & 5.030380 & 0.128674 & $39.094^{\star * *}$ & 1016.564203 & & & & \\
\hline L2 IV: EI & & & & & 0.268674 & 0.468694 & 0.573 & 1017.766846 \\
\hline
\end{tabular}

Note: DV = dependent variable, $\mathrm{L} 2=$ level $2, \mathrm{IV}=$ independent variable, $S E=$ standard error, $T=$ t-ratio. ${ }^{\star} p<0.05,{ }^{\star *} p<0.01,{ }^{* * *} p<0.001$.

faction or pupils' perceived autonomy support.

In order to examine the relationship between PE teachers' trait EI self-control and their relatedness-empathy, the relevance of these two sub-components within the EI-empathy relationship should be discussed. The EI self-control subscale comprises the factors of emotion regulation, impulsiveness (low) and stress management. As these factors represent intrapersonal skills, it is surprising that they relate to interpersonal processes (e.g. need empathy). However, that these intrapersonal skills were found to specifically link to need empathy suggests that teachers must first control themselves before they are able to perceive pupils' needs (Jennings \& Greenberg, 2009). Anxiety and worry, for example, are likely to impair a teacher's capacity to accurately perceive pupils' emotional states and need satisfaction. To summarise, the EI factor of selfcontrol, particularly the emotion regulation dimension, would ameliorate the inhibitive effects of negative emotion on perception by curbing negative emotional reactions during task engagement (Kanfer, Ackerman, \& Heggestad, 1996).

The role of EI self-control in helping a PE teacher to remain attentive to interpersonal emotional information in the potentially stressful classroom environment is supported by the results of Mikolajczak, Roy, Verstrynge, and Luminet (2009). Mikolajczak et al. showed that high EI self-control individuals, in comparison to low EI self-control individuals, demonstrated greater attention to emotional material and concurrently less mood deterioration following a suc- 
cessful stress induction. However, it is surprising that the EI emotionality subscale, which includes trait empathy as a factor, did not relate to need empathy. It is possible that this subscale contains conflicting factors for PE teachers: the ability to hold fulfilling relationships, for example, is unlikely to be scored highly for PE teachers working with younger school pupils. Moreover, the emotion perception factor within the EI emotionality subscale pertains to emotion in both oneself and others, although there may be a disparity between these emotional abilities in PE teachers.

That relatedness-empathy, but not competence- or autonomy-empathy, was found to be linked to EI can be explained by the opportunities PE teachers have to estimate need satisfaction in their pupils. Relatedness is likely to be perceptible to PE teachers when observing the interpersonal behaviours of pupils. For example, in the formation of smaller groups or pairings within PE classes (a common and effective strategy to enhance learning; Shimon, 2011), it is likely that pupils with high relatedness satisfaction will be enthusiastic to form groups or pair up with friends, and vice versa. Thus, PE teachers' perception and recollection of these emotional displays within peer relationships help them to estimate their provision of support for relatedness. Considering the other empathy variables (i.e. competence and autonomy), the mean score for competence-empathy across teams was actually higher than relatedness-empathy, although it did not emerge as significantly related to EI variables. This finding is indicative of the PE setting: PE teachers must instruct and assess individual pupils according to a set curriculum. Teachers will, therefore, have an impression as to whether the majority of pupils are progressing or overwhelmed (the latter perhaps repre senting a clearer indication of a lack of competence satisfaction). The characteristics of the PE context also explain why teachers accurately perceived autonomy satisfaction regardless of their EI, as there are limited opportunities to provide choice within a set teaching curriculum (Haerens et al., 2013) and thus teachers do not expect pupils to report high levels of autonomy satisfaction. In summary, it is likely that EI was not required for teachers to recognise the limited opportunities for pupils to make choices or decisions. However, this line of argumentation regarding autonomy is somewhat undermined by the high mean score for pupils' perceived autonomy support $(5.03, \mathrm{SD}=1.24)$, although only two items from the six item SCQ questionnaire pertain to autonomy and the remainder to competence and relatedness.

Beyond the perception of pupils' need satisfaction, PE teachers' EI could have been expected to directly relate to pupils' need satisfaction, although no such relationship was identified in the current study. Our findings are inconsistent with related research: Haerens et al. (2013) compared expert observation and pupils' perspectives and reported that relatedness support from PE teachers' was strongly characterised by being empathic, enthusiastic and attentive to pupils' questions, emotional qualities that reflect factors within the emotionality (i.e. trait empathy, emotion expression) and sociability (i.e. social awareness) subscales of trait EI. It may, therefore, be worthwhile for further research to use observation techniques to explore whether PE teachers' self-reported trait EI scores reflect their 
actual behaviours.

Furthermore, no significant relationships were found between PE teachers' EI and pupils' perceived autonomy support, despite the underlying emotional prerequisites of supportive behaviours that are well documented in the literature. Magyar et al. (2007), for example, showed that sports leaders' regulation of their own emotions, part of the EI self-control subscale, is positively related to their personal caring towards followers. Similarly to autonomy support, caring leaders are open-minded and responsive towards individuals, concerned with their followers' well-being, and value each individual's input (Cothran, Kulinna, \& Garrahy, 2003). For pupils within the PE context, a greater perception of caring from the teacher increases their engagement in PE (Cothran \& Ennis, 2000), which would be expected to stem from increased need satisfaction. Magyar et al. (2007) suggest that leaders' emotion regulation allows them to remain objective and responsive to the needs of their followers and subsequently demonstrate effective support behaviours. Given these arguments that support a link between EI and autonomy support, future research should seek to replicate our findings.

Our study has a few limitations regarding the design, data structure and the assessed questionnaire. Regarding the design of our study, the cross sectional approach prevents the determination of causality. It may be the case that PE teachers derived their EI traits from their perceptions of pupils' emotion. Regarding the data structure, PE teachers only completed one CBANS questionnaire for their respective class, rather than individual questionnaires for each class member. Although CBANS questionnaires completed for each pupil would have provided a more accurate assessment of PE teachers' need empathy values, the practical time constraints make this approach unfeasible. Finally, regarding the assessed questionnaire, the lack of significant findings could indicate a shortcoming of using the short form TEIQue within the PE context. It might be the case that specific factors, which are assessed individually in the long form of the TEIQue, appear important for teachers over others within the same subscale. Moreover, a larger sample of PE teachers would have been preferable to allow a meaningful inspection of subscale reliability.

\section{Conclusion}

In conclusion, our findings offer only minor support for a relationship between $\mathrm{PE}$ teachers' EI and pupils' motivation. Although the link between PE teachers' EI self-control and the accurate perception of pupils' relatedness represents a potentially important finding, further research is required to: 1) confirm this link; 2) identify how self-control aids teachers' perception of need satisfaction (e.g. by protecting against ego depletion); and, 3) to examine how, if at all, this improved perception aids PE teachers in satisfying the needs of pupils and developing their motivation towards PE.

\section{Declaration of Conflicting Interests}

The authors declare that there is no conflict of interest. 


\section{References}

Barkoukis, V., \& Hagger, M. S. (2009). A Test of the Trans-Contextual Model of Motivation in Greek High School Pupils. Journal of Sport Behavior, 32, 152-174.

Brackett, M. A., Palomera, R., Mojsa, J., Reyes, M., \& Salovey, P. (2010). Emotional Regulation Ability, Job Satisfaction, and Burnout among British Secondary School Teachers. Psychology in the Schools, 47, 406-417.

Brasseur, S., Grégoire, J., Bourdu, R., \& Mikolajczak, M. (2013). The Profile of Emotional Competence (PEC): Development and Validation of a Self-Reported Measure That Fits Dimensions of Emotional Competence Theory. PLoS ONE, 8, e62635. https://doi.org/10.1371/journal.pone.0062635

Chan, J. T., \& Mallett, C. J. (2011). The Value of Emotional Intelligence for High Performance Coaching. International Journal of Sports Science and Coaching, 6, 315-328. https://doi.org/10.1260/1747-9541.6.3.315

Chang, L. (2003). Variable Effects of Children's Aggression, Social Withdrawal, and Prosocial Leadership as Functions of Teacher Beliefs and Behaviors. Child Development, 74, 535-548. https://doi.org/10.1111/1467-8624.7402014

Cothran, D. J., \& Ennis, C. D. (2000). Building Bridges to Student Engagement: Communicating Respect and Care for Students in Urban High Schools. Journal of Research and Development in Education, 33, 106-117.

Cothran, D. J., Kulinna, P. H., \& Garrahy, D. A. (2003). This is Kind of Giving a Secret away...: Students' Perspectives on Effective Class Management. Teaching and Teacher Education, 19, 435-444. https://doi.org/10.1016/S0742-051X(03)00027-1

Cox, A., Duncheon, N., \& McDavid, L. (2009). Peers and Teachers as Sources of Relatedness Peceptions, Motivation, and Affective Responses in Physical Education. Research Quarterly for Exercise and Sport, 80, 765-773.

https://doi.org/10.1080/02701367.2009.10599618

Deci, E. L., \& Ryan, R. M. (1985). Intrinsic Motivation and Self-Determination in Human Behavior. New York: Plenum Press. https://doi.org/10.1007/978-1-4899-2271-7

Deci, E. L., \& Ryan, R. M. (1987). The Support of Autonomy and the Control of Behaviour. Journal of Personality and Social Psychology, 53, 1024-1037.

https://doi.org/10.1037/0022-3514.53.6.1024

Deci, E. L., \& Ryan, R. M. (2000). The "What" and "Why" of Goal Pursuits: Human Needs and the Self-Determination of Behavior. Psychological Inquiry, 11, 227-268. https://doi.org/10.1207/S15327965PLI1104_01

Freudenthaler, H. H., Neubauer, A. C., Gabler, P., Scherl, W. G., \& Rindermann, H. (2008). Testing and Validating the Trait Emotional Intelligence Questionnaire (TEIQue) in a German-Speaking Sample. Personality and Individual Differences, 45, 673-678.

Goudas, M., Dermitzaki, I., \& Bagiatis, K. (2001). Motivation in Physical Education Is Correlated with Participation in Sport after School. Psychological Reports, 88, 491-496. https://doi.org/10.2466/pr0.2001.88.2.491

Haerens, L., Aelterman, N., Van den Berghe, L., De Meyer, J., Soenens, B., \& Vansteenkiste, M. (2013). Observing Physical Education Teachers' Need-Supportive Interactions in Classroom Settings. Journal of Sport and Exercise Psychology, 35, 3-17. https://doi.org/10.1123/jsep.35.1.3

Jennings, P. A., \& Greenberg, M. T. (2009). The Prosocial Classroom: Teacher Social and Emotional Competence in Relation to Student and Classroom Outcomes. Review of Educational Research, 79, 491-525.

https://doi.org/10.3102/0034654308325693 
Kanfer, R., Ackerman, P. L., \& Heggestad, E. D. (1996). Motivational Skills and Self-Regulation for Learning: A Trait Perspective. Learning and Individual Differences, $8,185-209$.

Kleinert, J. (2012). Kontextuelle bedürfnisbefriedigung: Erste erfahrungen mit einem diagnostiktool für die sportpsychologische forschung und betreuung [Contextual Need Satisfaction: First Experiences with a Diagnostic Tool for Research and Counselling in Sport Psychology]. In M. Wegner, J. P. Brückner, \& S. Kratzenstein (Eds.), Sport- psychologische Kompetenz und Verantwortung (pp. 96). Hamburg: Feldhaus.

Laborde, S., Dosseville, F., \& Allen, M. S. (2016). Emotional Intelligence in Sport and Exercise: A Systematic Review. Scandinavian Journal of Medicine and Science in Sports, $26,862-874$.

Mageau, G. A., \& Vallerand, R. J. (2003). The Coach-Athlete Relationship: A Motivational Model. Journal of Sports Sciences, 21, 883-904. https://doi.org/10.1080/0264041031000140374

Magyar, M. T., Guivernau, M. R., Gano-Overway, L. A., Newton, M., Kim, M. S., Watson, D. L., \& Fry, M. D. (2007). The Influence of Leader Efficacy and Emotional Intelligence on Personal Caring in Physical Activity. Journal of Teaching in Physical Education, 26, 310-319. https://doi.org/10.1123/jtpe.26.3.310

Mayer, J. D., \& Salovey, P. (1997). What Is Emotional Intelligence? In P. Salovey, \& D. J. Sluyter (Eds.), Emotional Development and Emotional Intelligence: Educational Implications (pp. 3-31). New York, NY: Basic Books.

Mikolajczak, M., Roy, E., Verstrynge, V., \& Luminet, O. (2009). An Exploration of the Moderating Effect of Trait Emotional Intelligence on Memory and Attention in Neutral and Stressful Conditions. British Journal of Psychology, 100, 699-715. https://doi.org/10.1348/000712608X395522

Mouratidis, T., Vansteenkiste, M., Lens, W., \& Vanden Auweele, Y. (2009). Beyond Positive and Negative Affect: Achievement Goals and Discrete Emotions in the Elementary Physical Education Classroom. Psychology of Sport and Exercise, 10, 336-343.

Mouton, A., Hansenne, M., Delcour, R., \& Cloes, M. (2013). Emotional Intelligence and Self-Efficacy among Physical Education Teachers. Journal of Teaching in Physical Education, 32, 342-354. https://doi.org/10.1123/jtpe.32.4.342

Nezlek, J. B. (2008). An Introduction to Multilevel Modeling for Social and Personality Psychology. Social and Personality Psychology Compass, 2, 842-860. https://doi.org/10.1111/j.1751-9004.2007.00059.x

Ntoumanis, N. (2005). A Prospective Study of Participation in Optional School Physical Education Using a Self Determination Theory Framework. Journal of Educational Psychology, 97, 444-453. https://doi.org/10.1037/0022-0663.97.3.444

Petrides, K. V. (2009a). Psychometric Properties of the Trait Emotional Intelligence Questionnaire (TEIQue). In C. Stough, D. H. Saklofske, \& J. D. A. Parker (Eds.), Assessing Emotional Intelligence: Theory, Research, and Applications (pp. 85-101). New York, NY: Springer Science. https://doi.org/10.1007/978-0-387-88370-0_5

Petrides, K. V. (2009b). Technical Manual for the Trait Emotional Intelligence Questionnaire (TEIQue). London: London Psychometric Laboratory.

Petrides, K. V., \& Furnham, A. (2003). Trait Emotional Intelligence: Behavioural Validation in Two Studies of Emotion Recognition and Reactivity to Mood Induction. European Journal of Personality, 17, 39-57. https://doi.org/10.1002/per.466

Petrides, K. V., Pita, R., \& Kokkinaki, F. (2007). The Location of Trait Emotional Intelligence in Personality Factor Space. British Journal of Psychology, 98, 273-289. 
https://doi.org/10.1348/000712606X120618

Raudenbush, S. W., \& Bryk, A. S. (2002). Hierarchical Linear Models. Applications and Data Analysis Methods (2nd ed.). Thousand Oaks, CA: Sage Publications.

Raven, H., \& Kleinert, J. (2016). Den eigenen Fähigkeiten vertrauen-Die Rolle von Selbstwirksamkeitserwartung und psychologischen Grundbedürfnissen im Schulsport [Trusting One's Own Abilities-The Role of Self-Efficacy and Psychological Basic Needs in School Sports]. Sportunterricht, 65, 113-118.

Ryan, R. M., \& Deci, E. L. (2000). Self-Determination Theory and the Facilitation of Intrinsic Motivation, Social Development, and Well-Being. American Psychologist, 55, 68-78. https://doi.org/10.1037/0003-066X.55.1.68

Shimon, J. (2011). Introduction to Teaching Physical Education: Principles and Strategies. Champaign, IL: Human Kinetics.

Smith, N., Tessier, D., Tzioumakis, Y., Fabra, P., Quested, E., Appleton, P., Sarrazin, P., Papaioannou, A., Balaguer, I., \& Duda, J. L. (2016). The Relationship between Observed and Perceived Assessments of the Coach-Created Motivational Environment and Links to Athlete Motivation. Psychology of Sport and Exercise, 23, 51-63.

Standage, M., Duda, J. L., \& Ntoumanis, N. (2005). A Test of Self-Determination Theory in School Physical Education. British Journal of Educational Psychology, 75, 411-433. https://doi.org/10.1348/000709904X22359

Stebbings, J., Taylor, I. M., \& Spray, C. (2011). Antecedents of Perceived Coach Autonomy Supportive and Controlling Behaviors: Coach Psychological Need Satisfaction and Well-Being. Journal of Sport and Exercise Psychology, 33, 255-272.

Sutton, R. E., \& Wheatley, K. (2003). Teachers' Emotions and Teaching: A Review of the Literature and Directions for Future Research. Educational Psychology Review, 15, 327. https://doi.org/10.1023/A:1026131715856

Taylor, I. M., \& Lonsdale, C. (2010). Cultural Differences in the Relationships among Autonomy Support, Psychological Need Satisfaction, Subjective Vitality, and Effort in British and Chinese Physical Education. Journal of Sport and Exercise Psychology, 32, 655-673. https://doi.org/10.1123/jsep.32.5.655

Taylor, I. M., \& Ntoumanis, N. (2007). Teacher Motivational Strategies and Student Self-Determination in Physical Education. Journal of Educational Psychology, 99, 747760. https://doi.org/10.1037/0022-0663.99.4.747

Tschannen-Moran, M., Woolfolk-Hoy, A., \& Hoy, W. K. (1998). Teacher Efficacy: Its Meaning and Measure. Review of Educational Research, 68, 202-248. https://doi.org/10.3102/00346543068002202

Tsouloupas, C. N., Carson, R. L., Matthews, R., Grawitch, M. J., \& Barber, L. K. (2010). Exploring the Association between Teachers' Perceived Student Misbehavior and Emotional Exhaustion: The Importance of Teacher Efficacy Beliefs and Emotion Regulation. Educational Psychology, 30, 173-189. https://doi.org/10.1080/01443410903494460

Williams, G. C., Grow, V. M., Freedman, Z. R., Ryan, R. M., \& Deci, E. L. (1996). Motivational Predictors of Weight Loss and Weight-Loss Maintenance. Journal of Personality and Social Psychology, 70, 115-126.

https://doi.org/10.1037/0022-3514.70.1.115 
Submit or recommend next manuscript to SCIRP and we will provide best service for you:

Accepting pre-submission inquiries through Email, Facebook, LinkedIn, Twitter, etc. A wide selection of journals (inclusive of 9 subjects, more than 200 journals)

Providing 24-hour high-quality service

User-friendly online submission system

Fair and swift peer-review system

Efficient typesetting and proofreading procedure

Display of the result of downloads and visits, as well as the number of cited articles Maximum dissemination of your research work

Submit your manuscript at: http://papersubmission.scirp.org/

Or contact ape@scirp.org 